\title{
ENTER THE TWILIGHT ZONE: THE PARADOX OF THE DIGITAL NATIVE
}

\author{
Nancy Marksbury, Keuka College,nmarksbury@keuka.edu \\ Enid Arbelo Bryant, Keuka College, ebryant@keuka.edu
}

\begin{abstract}
This study explored undergraduate students' self-reports of their digital literacy across the domains of information, communication, content creation, safety, problem solving, copyright awareness, social media participation and basic technical skills. An exploratory factor analysis was conducted, identifying 7 factors explaining students' multidimensional digital literacy. Students' self-exploration remained the driving force for their digital skills, yet transferring those skills developed over the years in texting, gaming and social media participation to the classroom does not appear to happen naturally. Information literacy and emerging cybersecurity awareness are two additional factors that help us understand the paradox of the digital native. Implications for higher education curricula are discussed.
\end{abstract}

Keywords: digital literacy, digital native, critical thinking, metacognition, information literacy, cybersecurity

\section{INTRODUCTION}

As educators we have grown accustomed to classrooms of students consumed by technology. We are met with a void stare, a face illuminated by the reflection of the bright screen that buzzes and blinks from constant notifications. In efforts to harness the same kind of power over students as these black mirrors that hold mystery and delight, we are compelled to understand how our students obtain these skills and how these tools impact their education. Ironically, while their fingers seem so nimble on these personal digital devices, we are surprised to find they are less likely to transfer technology skills to the classroom despite common misconceptions of their supposed digital prowess.

\section{Digital Native or Not?}

College students today and typically anyone born after 1980 - known to many as digital natives - represent a generation of young people who grew up with technology in their lives since birth (Prensky, 2001). Today's adults, college-aged students, adolescents, and even children - based on Prensky's definition - fall into a group capable of a unique set of skills based on the notion that they grew up in a world where technology was present and constantly evolving. "It is now clear that as a result of this ubiquitous environment and the sheer volume of their interaction with it, today's students think and process information fundamentally differently from their predecessors (Prensky, 2001)." Prensky goes on to tell us that these students are "all 'native speakers' of the digital language of computer, video games and the Internet." These young people thrive on the instant gratification of the digital world where they can receive information quickly and multitask in a space that enables them to choose entertainment over serious work (Prensky, p.2, 2001).

But some argue that this so-called digital savviness based on generation does not always hold true (Kirschner \& Bruyckere, 2017). We notice in our classrooms these digital natives have a singular approach to finding and processing information, which is web-first and very trusting of web sources. Students tend to be consumers rather than producers, unaware of the inner workings of the Internet, including the dubious nature of platforms where they become frequent inhabitants, such as social media. Research studies across half a dozen countries have questioned whether this idea of a digital native actually exists and, in response, if teaching and learning should be adjusted to ensure students are getting what they need from institutions of higher education. Researchers report that "university students, all born after the magical year 1984, do not have deep knowledge of technology," and the skills that emerge from that constant digital practice doesn't extend beyond basic emailing, texting, social media use and surfing the web (Kirschner \& Bruyckere, 2017). They argue that significant further training in how technology can be used for learning and problem solving is needed for college students to ensure they move beyond passive 


\section{Issues in Information Systems}

Volume 20, Issue 2, pp. 206-215, 2019

consumption of digital technology. For example, dexterity on social media platforms should not be confused with digital literacy. So what is it we are trying to measure after all?

\section{Digital Literacy Defined}

It has been difficult to come to a national or international consensus on the definition of digital literacy - most frameworks share characteristics but each varying definition agrees there is no focus on a single skill or approach but most can agree it is a prerequisite for survival and success in the $21^{\text {st }}$ century. Briggs \& Makice (2012) define digital literacy as technical adeptness for achieving desired outcomes. Hsi (2007) assigns proficiency over digital information to enable innovation and problem solve. In today's classroom, being digitally literate means to be able to understand the influence of digital media on our society, develop strategies to critically analyze it, become independent from its influence, and open to new tools (Sadaf \& Johnson, 2017). Of the 18.6 million students (Pew Research Center, 2018) enrolled in higher education institutions, $88 \%$ own laptops, $85 \%$ own smartphones, and $50 \%$ own a tablet. These tools are ubiquitous on college campuses but the ability to use these tools for literacy or learning varies greatly. Meanwhile, educators, prospective employers, and society in general expect and assume recent graduates to demonstrate agile digital literacy skills, which have become somewhat conflated with technological literacy or hard skills such as software use or coding.

How can we better understand who our students are and the level of their digital literacy skills? These questions were the beginning of an internal assessment of our students at a small liberal arts college in western New York. Realizing that our students were not coming into college with what we perceived as basic digital literacy skills, we needed to evaluate the skills they have and still need to acquire.

In exploring recent work on assessing digital literacy skills, multiple theoretical models drive the evaluation of digital literacy. Measuring digital literacy requires evaluation of several subdomains, e.g., information, communication, content-creation, safety, and problem solving, among others. We drew from the systematic review of assessments performed by Siddiq, Hatlevik, Olsen, Throndsen \& Scherer (2016). While their comprehensive review focused on measuring digital competencies in Europe among secondary school students, we found the revised DIGCOMP framework in good alignment with meaningful skill categories. Among other studies, potential confounds were identified. Owens \& Lilly (2017) reported gender and race were most strongly associated with Internet skills among the graduate students they studied; academic discipline-type also attributed in varying degrees to skills demonstrated. These demographic qualifiers were included in the instrument created for this assessment, with prompts for levels of parent education, given many students' first-generation status at the institution. Item prompts were added to assess information literacy, copyright licensing, protecting personal data, netiquette, collaborative work (Kurtz \& Peled, 2016); social media participation (Koc \& Barut, 2016); as well as problem solving and basic technical skills (van Deursen, Helsper \& Eynon, 2016).

\section{RESEARCH METHODOLOGY}

To better understand the depth and breadth of our students' digital literacy skill levels, an exploratory study was designed to obtain skill self-assessments by students and their performance measures on tasks related to components comprising our operationalization of digital literacy. No hypotheses were generated.

A convenience sample of 164 students participated in this study by completing the consent form and online survey. Twelve international students were dropped from the analysis, given their outlying results on the performance tasks, thus yielding 152 participants, deriving from a population that $47 \%$ of whom are Pell grant eligible. The study was approved by the college's Institutional Review Board and conducted in the spring semester of 2018. Of those, 100 participants identified as female (66\%) with 52 identifying as male (34\%), matching the gender composition of the institution. Because "digital nativity" is purported to hold true for those born since the mid-80's, students' mean age was examined and are displayed in Table 1. 


\section{Issues in Information Systems}

Volume 20, Issue 2, pp. 206-215, 2019

Table 1. Student Characteristics as a Percentage of the Sample

\begin{tabular}{lrrrr}
\hline Characteristic & Freshmen $(n=42)$ & Sophomore $(n=39)$ & Junior $(n=46)$ & Senior $(n=25)$ \\
\hline Female & $29(69 \%)$ & $25(64 \%)$ & $33(72 \%)$ & $13(52 \%)$ \\
Male & $13(31 \%)$ & $14(36 \%)$ & $13(28 \%)$ & $12(48 \%)$ \\
Ethnicity & & & & \\
Caucasian & $27(64 \%)$ & $33(85 \%)$ & $42(91 \%)$ & $20(80 \%)$ \\
African-American & $5(12 \%)$ & $3(8 \%)$ & $1(2 \%)$ & $1(4 \%)$ \\
Asian & 0 & 0 & $1(2 \%)$ & $2(8 \%)$ \\
Hispanic & $8(19 \%)$ & $2(5 \%)$ & $1(2 \%)$ & 0 \\
Other & $2(5 \%)$ & $1(3 \%)$ & $1(2 \%)$ & $2(8 \%)$ \\
Mean Age & 19 & 20 & 20 & 22 \\
Mom Education & $1(2 \%)$ & $1(2 \%)$ & & 0 \\
Prefer not to answer & $4(10 \%)$ & $1(2 \%)$ & $1(1 \%)$ & 0 \\
No high school degree & $16(38 \%)$ & $18(46 \%)$ & $23(50 \%)$ & $10(40 \%)$ \\
No college degree & $21(50 \%)$ & $19(49 \%)$ & $23(50 \%)$ & $14(56 \%)$ \\
College degree & & & & $3(12 \%)$ \\
Dad Education & $6(14 \%)$ & 0 & $2(4 \%)$ & 0 \\
Prefer not to answer & $7(17 \%)$ & $4(10 \%)$ & $1(2 \%)$ & $8(32 \%)$ \\
No high school degree & $18(43 \%)$ & $19(49 \%)$ & $19(41 \%)$ & $13(52 \%)$ \\
No college degree & $11(26 \%)$ & $16(41 \%)$ & $25(54 \%)$ & $12(48 \%)$ \\
College degree & & & & $6(24 \%)$ \\
Major Types & $14(33 \%)$ & $16(41 \%)$ & $15(33 \%)$ & $7(28 \%)$ \\
Liberal Arts & $17(40 \%)$ & $10(26 \%)$ & $18(46 \%)$ & $13(33 \%)$ \\
Professional & $11(26 \%)$ & $13(33 \%)$ & & \\
STEM/Health & & &
\end{tabular}

Note: Sums of percentages may not exactly equal $100 \%$ due to rounding errors.

Student participants' mean age fell well within the digital native birth range, the oldest of whom were born in 1997 and likely grew up with access to a computer at home and at school. From an ethnicity standpoint, our sample is very homogeneous with little diversity, but representational of the student body. However, freshmen in this sample were the most diverse class. According to Zehner (1981), parents' educational level predicts a student's tendency to pursue college, and so we asked our subjects about their parents' level of education. It is interesting to note that freshmen were more likely than others to defer answering about their father's education, more so than their mother's: $31 \%$ of freshmen either preferred not to answer or noted their father did not hold a high school diploma. Finally, majors of our participants are divided into three broad categories of study.

Other demographic information collected includes students' self-reports of technology infusion in their high school coursework. Students were asked to indicate the frequency of using computer applications into aspects of their academic and non-academic lives. Figure 1. depicts the percentages of reports for never and frequent (weekly to several times per week) technology integration. 

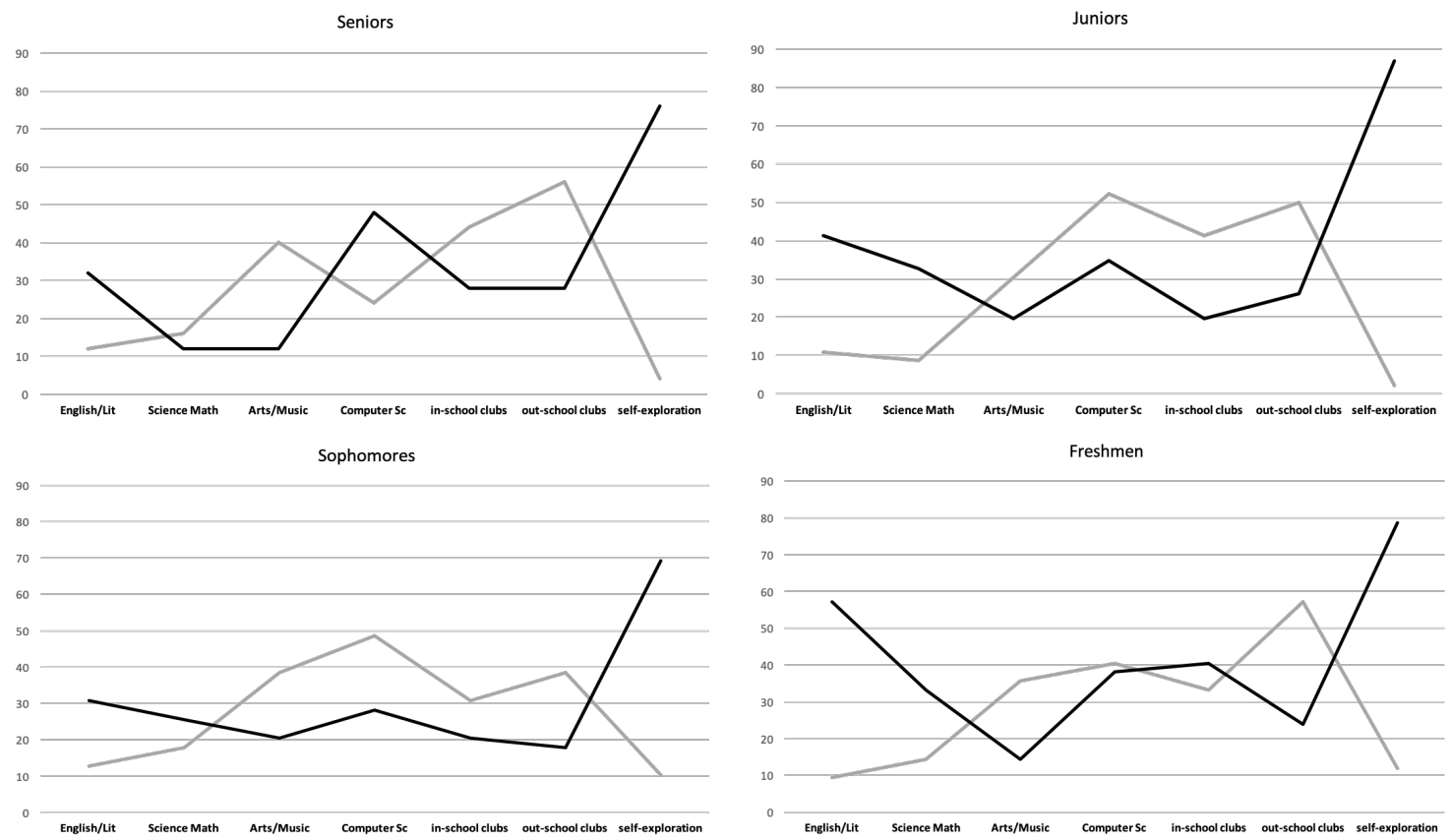

Figure 1. Comparison of High School Technology Integration by Subject and by Undergraduate Class.

Note: "Never" is represented in grey; a frequency of "weekly or more frequently per semester" is in black.

Despite the perceived ubiquity of 1:1 device deployments in public school systems, nationally funded programs like CS for All and robotics clubs, students in this sample do not appear to have benefitted from those experiences. Technology infusion in Science and Math coursework appear to be increasing based on reports of freshmen and juniors (33\%), yet only $18 \%$ of sophomores recall technology-enhanced instruction in those courses. More seniors noted never utilizing tech-infused instruction in Science and Math than did those reporting frequent activities. For Computer Science (CS) instruction, $48 \%$ of seniors reported a high frequency of integrated technology, but $24 \%$ reported no technology-infused instruction in CS. Fifty-two to $40 \%$ of all other participants reported never having technology-infused instruction in CS. Among all our participants, however, an extraordinarily high frequency is noted for technology self-exploration, ranging from $70-87 \%$. These observations are made in light of the fact that some participants' memory of their high school curricula may not be fully accurate.

\section{RESULTS}

To distill the results of the survey into its most simple structure, an exploratory factor analysis was performed using SPSS 24.0 with the principal axis factoring method on the variables. Multiple iterations of the factor analysis were required to identify survey items that cross-loaded on multiple factors or did not load at all. From the remaining 26 items, extracted factors were then rotated obliquely using the Varimax method with Kaiser normalization. The Kaiser Meyer-Olkin value was .764, exceeding the recommended value of .6 (Kaiser, 1960). Barlett's Test of Sphericity (Bartlett, 1954) reached statistical significance, supporting the factorability of the correlation matrix. Factor loadings exceeding .40 were considered in interpreting and labeling the factors. Based on Kaiser's stopping rule (i.e., eigenvalue $>1.0$ ), seven factors were extracted. Considering the scree plot, eigenvalues and a subsequent parallel analysis, a 7-factor solution was favored. Figure 2. illustrates the plotting of the results of the parallel analysis. 


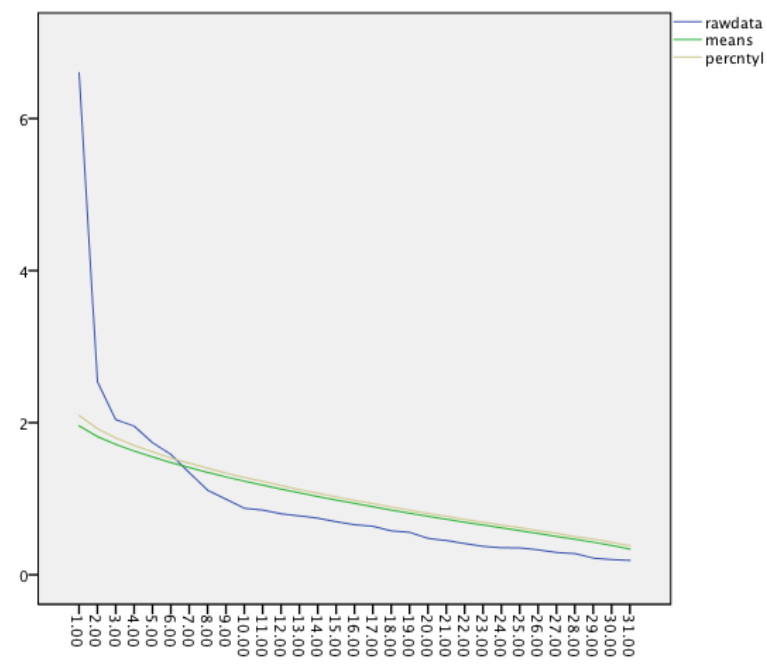

Figure 2. The 7-factor solution and recommended cutoff obtained by the parallel analysis.

The factor analysis revealed an underlying structure with seven latent variables that explain $60 \%$ of the variance of the data. Using the factor scores from the oblique rotation, the following latent constructs were identified: Factor 1Social media literacy (eigenvalue 6.07), explained $22 \%$ of the shared variance; Factor 2-Information literacy (eigenvalue 2.33), explained $8 \%$ of the shared variance; and Factor 3-Emerging cybersecurity awareness (eigenvalue 1.99), explained $7 \%$ of the shared variance. Factor 4-Critical problem solving (eigenvalue 1.83 ), explained $7 \%$ of the shared variance; Factor 5-Framing/dialectical thinking (eigenvalue 1.62), explained $6 \%$ of the shared variance; Factor 6-File management (eigenvalue 1.54), explained 5\% of the shared variance; and Factor 7-Learning disposition (eigenvalue 1.31), explained $5 \%$ of the shared variance. Item wordings and factor loadings are shown in Table 2.

Table 2. Items and Factor Loadings with Varimax Rotation of Digital Literacy items

\begin{tabular}{|c|c|c|c|c|c|c|c|}
\hline Item & $\mathrm{F} 1$ & $\mathrm{~F} 2$ & F3 & $\mathrm{F} 4$ & F5 & F6 & F7 \\
\hline $\begin{array}{l}\text { It is easy for me to create user accounts and profiles in media } \\
\text { environments. }\end{array}$ & .60 & .09 & .18 & .20 & .16 & .08 & -.04 \\
\hline can use hardware necessary for developing media contents. & .67 & .18 & .08 & 29 & .06 & -.08 & .03 \\
\hline $\begin{array}{l}\text { I can make a contribution/comments to media contents shared by } \\
\text { others. }\end{array}$ & .66 & .12 & .11 & .03 & .02 & .18 & -.01 \\
\hline $\begin{array}{l}\text { I am able to rate/review media contents based on my personal } \\
\text { interests and liking. }\end{array}$ & .73 & .18 & .14 & .04 & .02 & .15 & -.09 \\
\hline am able to use software necessary for developing media content. & .60 & .19 & 10 & .05 & 10 & .01 & .04 \\
\hline kno & .13 & .48 & .25 & .22 & 27 & .18 & -.08 \\
\hline can $\mathrm{c}$ & .22 & .70 & .11 & .10 & .20 & .16 & -.05 \\
\hline I am & .08 & .61 & .08 & .13 & -.05 & .10 & .06 \\
\hline I can & .17 & .61 & -.01 & .08 & -.02 & .11 & .05 \\
\hline nation from databases. & .27 & .59 & .10 & .25 & .10 & .15 & -.04 \\
\hline & .13 & .08 & .63 & -.01 & -.03 & .02 & .08 \\
\hline fe & .20 & -.03 & .68 & .09 & .24 & 12 & -.01 \\
\hline kno & .13 & .14 & .72 & .20 & .09 & .07 & .03 \\
\hline $\begin{array}{l}\text { I produce content respectful to people's different ideas and private } \\
\text { lives. }\end{array}$ & .05 & .09 & .48 & -.01 & .11 & .09 & .10 \\
\hline I find it easy to $u$ & .31 & -.02 & .06 & .58 & -.08 & -.08 & .08 \\
\hline $\begin{array}{l}\text { Encountering a new software program, I am confident I can learn it } \\
\text { quickly. }\end{array}$ & .23 & .12 & -.05 & .60 & .01 & -.02 & .12 \\
\hline The way in which many websites are designed is often confusing. & -.04 & .07 & .02 & .50 & .08 & .11 & -.07 \\
\hline I get tired when looking for information online. & -.01 & .18 & 17 & .48 & .02 & -.01 & .03 \\
\hline
\end{tabular}




\section{Issues in Information Systems}

Volume 20, Issue 2, pp. 206-215, 2019

\begin{tabular}{|c|c|c|c|c|c|c|c|}
\hline $\begin{array}{l}\text { I know how to adjust privacy settings on the social media platforms } \\
\text { I'm on. }\end{array}$ & .12 & .17 & .09 & .43 & 12 & .10 & -.06 \\
\hline arting a group project, I typically know what is expected of me. & .09 & .10 & .16 & 41 & .63 & -.01 & .07 \\
\hline $\begin{array}{l}\text { uring the preparation of a collaborative/group project, I know that } \\
\text { have an influence on the work process. }\end{array}$ & .14 & .08 & .16 & .06 & .79 & .09 & .01 \\
\hline $\begin{array}{l}\text { ollaborative/group project, I know how } \\
\text { s. }\end{array}$ & 0 & -.03 & .01 & .08 & .56 & .33 & .30 \\
\hline specific name. & .02 & .16 & .14 & .01 & 0 & .71 & \\
\hline & .15 & .21 & -.01 & .02 & .08 & .62 & \\
\hline can & .19 & .14 & .20 & 11 & .19 & .62 & -.0 \\
\hline . & -.02 & .06 & 11 & .09 & .02 & -.03 & \\
\hline I with neerc on o collohorntive /oroun nroiect & .04 & -.01 & .11 & .01 & .11 & .03 & .75 \\
\hline would rather work by myself and not with peers. & -.05 & -.05 & -.05 & -.09 & .05 & -.03 & \\
\hline
\end{tabular}

Factor 1- Social media literacy is made up of five items that address students' behavior and abilities in social media spaces, such as their ability to engage with others in these online environments and their familiarity with hardware and software necessary to make these kinds of contributions. Social media - websites or applications for social networking and microblogging where users create online communities to share information, ideas, personal messages, and other content - are spaces where college-aged students spend a great deal of time while developing social presence and fulfilling a need to conform. While there are preferred social networking choices for young adults, $88 \%$ of this group says they will use any form of social media. They embrace a variety of platforms and use them frequently; for instance, $78 \%$ use Snapchat, and $71 \%$ of those viewers visit multiple times a day. Also, $45 \%$ are Twitter users and 71\% use Instagram (Pew Research Center, 2018).

The time spent on these sites is mainly to share informal and personal experiences with friends in an effort to maintain and improve social relationships (Porat, Blau \& Barak, 2018). There is less focus on using these tools for professional purposes or communication than with digital immigrants. Meanwhile, digital natives are assumed to perceive new technology to be easy to use. Based on a research study that focused on Twitter use disparity among generations, Metallo and Agrifoglio (2015) argue that digital natives do not see Twitter as a professional tool to be used in the workplace that requires training; instead these users focus on Twitter's entertainment features and learn to use these tools through "trial-and-error". Self-teaching doesn't seem to be enough, though. Porat et al., (2018) found that despite the consistent practice of using basic digital and social communication required of frequent social networking, students are not developing a mastery of these complex skills in an educational context. That means their performance actually tends to be mediocre at best and poor at worst when tasked with using digital devices that require critical thinking, and cognitive, social-emotional, and ethical dimensions for learning purposes. Given our subjects' frequency spent in technical self exploration, this confirms our classroom observations that their social media adeptness is not transferring to educational contexts.

Factor 2- Information literacy (IL) is comprised of five items. These items align with multiple frameworks that define the ability to articulate an information need, redefine that need into search terms a database or search engine can act on, and use those results for organizing one's understanding and resolving the information need (EshetAlkali \& Amichai-Hamburger, 2004, and Cordell, 2013). Çoklar, Yaman, \& Yurdakul (2017) established a high correlation of IL with online search competencies. Factor 2 also includes being able to re-locate information, and these items all demonstrate the shared areas of IL and digital literacy. The basics of information literacy are part of the undergraduate curriculum, which are likely to build upon the learning students gain in high school. Navigators of online information systems require cognitive planning that understands how online searches are conducted. A search is conducted, results reviewed, and keywords and/or other delimiters are refined. While much overlap exists between IL and digital literacy, scholars consider the two literacies as separate and distinct (Becker 2018, Cordell 2013).

Factor 3- Emerging cybersecurity awareness is formed from four items. While these items represent rudimentary concerns of a computer user, they are nonetheless the building blocks for steps to take for protecting one's personal information before a more complex understanding of potential cyber-attacks and their consequences can be assumed. A case study of undergraduates' understanding on the topic (Pawlowski \& Jung, 2015) revealed overall but superficial familiarity with the technical vocabulary and little evidence of concern with respect to cyber attacks 
on critical infrastructure. Their subjects' central awareness centered around the idea of hacker criminals. Nearly half of all subjects in our digital literacy assessment reported never having a tech-infused CS course. Given the corresponding high rates of self-exploration among subjects' technology experience, it follows that their responses to Factor 3 items stem from the elementary aspects of emerging cybersecurity awareness, and is likely the result of high school digital citizenship initiatives and ethics instruction.

Factor 4- Five items combined to form critical problem solving. These items capture novel experiences and how participants respond to uncertainty and ambiguity, particularly when encountering new applications and/or devices. It is interesting this factor contains two items that are worded negatively (The way in which many websites are designed is often confusing. And, I get tired when looking for information online.) Ill-structured problems are often encountered when using technology, and students often have to strive to understand the context of a problem before reaching a resolution. While critical problem solving on social media platforms occurs organically - researching cheats for a new game or deciding when to unfollow a "frenemy" - a disconnect appears when transferring those skills in the classroom or with coursework. Developing metacognitive strategies are imperative for problem solving while learning, and especially for success as an adult in the workforce (Sigler \& Tallent-Runnels, 2006). van Laar, van Deursen, van Dijk \& de Haan (2017) count critical thinking/problem solving among seven core skills that comprise $21^{\text {st }}$ century skills, not all of which are digitally-related.

Factor 5- Framing/dialectical thinking is comprised of three items concentrated on a students' role in collaborative settings and group projects. While students come to college with the naïve notion that they will learn the right answers and gain the wisdom to avoid the wrong approach, they are confused when they realize many problems have more than one solution (Colby, Ehrlich, Sullivan, Dolle, \& Shulman, 2011). In framing/dialectical thinking students are challenged to see beyond a preconceived perspective and draw from a range of experiences and disciplines to see various solutions to a problem or challenge (Colby et al., 2011). This skill is necessary to navigate the "pluralistic social contexts" in which education and industry exist. In particular, students must consider various aspects and layers of the problem - thinking beyond self and preconceived notions - and move beyond a narrow focus to come to an agreed upon resolution. In collaborative work settings, internship environments and even while working through interpersonal conflict, students can turn to dialectical thinking to develop various viewpoints and frame ways of thinking to lead to more thoughtful and effective problem solving (Colby et al., 2011).

Factor 6- Three items combined in loading on this factor to represent a skill central to electronic file management. In their assessment of incoming master's and doctoral students in South Africa, Blignaut \& Els (2010) noted that electronic file management skills were highly correlated with "comparacy" or a rudimentary knowledge of computer hardware and software. Individuals who fall into the generation prior to 1980, Prensky's digital immigrants, have the insight of pre-computer metaphors, drawing inferences between the computer interface and aspects of working with a physical desktop like files, folders, and file storage locations. While these "logical analogues" (Hamilton, 2000) worked in communicating new concepts to early computer users, today's computer users may not understand the relationship of icons and names within current computing environments. Still, these fundamental skills are essential for establishing more complex understandings.

Factor 7- The last factor - learning preferences/dispositions - is comprised of three items that address students' learning environment or style preferences, as in the difference between working independently or in a group. Learning dispositions or learning styles is a way to characterize how students perceive their learning environment and how they respond to that environment. Students are usually aware of their individual learning preferences and dispositions and research has shown that most students benefit from teaching that incorporates various styles of instruction (Bhagat, Vyas \& Singh, 2015). While accessing environments, students are faced with learning situations that are either self-regulated, where he or she is solely responsible for the activities and to meet expectations, or when those expectations are externally regulated by other group members and there is no regulation and support from the teacher (Bhagat et al., 2015). Finding the right preference for each learner depends on variables that stem from character dispositions. They can be inborn dispositions, such as innate curiosity, or social dispositions, which speak to the tendency to be accepting and collaborative, or lastly, intellectual dispositions, where students are defined as being curious and showing persistence (Katz, 1993). While the item loadings in this study appear contradictory, students preferred to work with others but still valued their autonomy. 


\section{Issues in Information Systems \\ Volume 20, Issue 2, pp. 206-215, 2019}

The function of an exploratory factor analysis is to reduce data in order to measure latent content, the internal attributes or hypothetical constructs routinely used throughout science (Tucker \& MacCallum, 1997). The exploratory factors in this analysis suggest that social media literacy is the prime driver of digital literacy. Students' skills are developed through social experimentation and are likely to reinforce consumption of information over production. Information literacy also plays a large role in their digital literacy skills; an emphasis on foundational cybersecurity awareness is noted. Critical thinking, dialectical thinking, electronic file management, and learning preferences also influence the digital literacy skill set among these participants.

This study has several limitations worth noting. The variance explained in this exploratory factor analysis is relatively low at $60 \%$. While the sample size for this analysis is adequate, a larger pool might have provided stronger or different results. Secondly, the items of this survey compiled from other studies were primarily developed for secondary students. van Laar et al., (2017) note most measurement tools target this age group. A more relevant set of items would likely yield clearer results among higher education students, graduate students and also employees. Thirdly, using only survey data results to assess students' digital literacy skills provides a superficial reading of students' skills. According to Siddiq et al., (2016), performance measures on technical tasks will provide a richer assessment for interpretation than a survey on its own. These limitations will be addressed in future work.

\section{SUMMARY}

This study explored undergraduate students' self-reports of their digital literacy across the domains of information, communication, content creation, safety, problem solving, copyright awareness, social media participation and basic technical skills. An exploratory factor analysis was conducted, identifying 7 factors explaining students' multidimensional digital literacy. The facets of digital literacy emerging from the present analysis align with the van Laar et al., (2017) framework of core $21^{\text {st }}$-century digital skills: Information management, communication, collaboration, creativity, critical thinking, problem solving and technical abilities. Social media may be a gateway by which digital natives conduct self-exploration and trial and error learning with technology, but the practice does not appear to be a vehicle for transferring skills to the educational context. Information literacy, on the other hand does connect to students' educational context as it is part of the undergraduate curriculum. The dimension of emerging cybersecurity awareness, in this study, reflects students' foundational understanding which can then be leveraged for a more discriminating and informed defense. Yet, few disciplines embed instruction to help students develop solid technical understanding in the context of individual protection, privacy and online safety. Given the insidious nature of fake update alerts and other social engineering approaches for attacking unsuspecting users (Heartfield \& Loukas, 2018), students need to learn how to employ critical thinking and metacognitive skills. Students who have mastery over digital literacy skills will be able to complete basic word processing tasks and understand a desktop but, more importantly, understand the influence of digital media on our society, how to analyze it, and how to use those skills to explore new tools in the future (Sadaf \& Johnson, 2017). If, as educators, we can support students and intervene appropriately throughout the college experience, the accrual of those skills will be more strategic and intentional, supporting our students in important ways after graduation.

The question then becomes how well higher education aligns curricula with the recognition of skills that prepare students for entering the information-rich and technology-based society, one that is tempered by a fit gap analysis of digital natives' actual abilities. Higher education, in particular, would be well advised to resist buying into overarching labels that assign abilities by generation. This is why it is illogical and even dangerous to lump students into a category that implies unrealized fluency. Assumptions like these have the potential to make instruction fall short. Students may well recognize a paradox of their own when they don't fit the digital native model.

Digital natives are also a paradox for many educators who are constantly reminded to change the way we teach to accommodate this generation. Prensky got it right and he had it wrong, too. Today's students are fundamentally different in how they acquire information and learn; their brains are different. However, today's digital native does not benefit from Prensky's advice to educators to "[go] faster, [and provide] less step-by step [instruction]" (2001, p. 4). It is our goal to empower future graduates with the knowledge and understanding of the true potential technology holds. We can make that connection for our students with a more intentional digital literacy approach that focuses on shifting the skills they already have - and the way they develop these skills - to professional and educational formats. 


\section{REFERENCES}

Bartlett, M.S. (1954). A note on multiplying factors for various Chi square approximations. Journal of the Royal Statistical Society. 16(Series B), 296-298.

Becker, B. (2018). Information literacy in the digital age: Myths and principles of digital literacy. School of Information Student Research Journal, 7(2). Available at: https://scholarworks.sjsu.edu/slissrj/vol7/iss2/2

Bhagat, A., Vyas, R., \& Singh, T. (2015). Students' awareness of learning styles and their perceptions to a mixed method approach for learning. International Journal of Applied \& Basic Medical Research, 5(Suppl 1), S58-S65. doi:10.4103/2229-516X.162281

Blignaut, A.S. \& Els, C.J. (2010). Comperacy assessment of postgraduate students' readiness for higher education. Internet \& Higher Education, 13(3), 101-107. doi.org/10.1016/j.iheduc.2010.02.007

Briggs, C., and Makice, K. (2011). Digital fluency. Available at http://socialens.com/fluencybook.php

Çoklar, A. N., Yaman, N. D., \& Yurdakul, I. K. (2017). Information literacy and digital nativity as determinants of online information search strategies. Computers in Human Behavior, 70, 1-9. doi.org/10.1016/j.chb.2016.12.050

Colby, A., Ehrlich, T., Sullivan, W.M., Dolle, J.R., \& Shulman, L.S. (2011). Rethinking Undergraduate Business Education: Liberal Learning for the Profession. Jossey-Bass: Stanford, CA.

Cordell, R. M. (2013). Information literacy and digital literacy: Competing or complementary? Communications in Information Literacy; Tulsa, 7(2), 177-183. doi.org/10.15760/comminfolit.2013.7.2.150

Eshet-Alkali, Y. \& Amichai-Hamburger, Y. (2004). Experiments in digital literacy. CyberPsychology \& Behavior, 7(40, 421-429. doi.org/10.1089/cpb.2004.7.421.

Hamilton, A. (2000). Interface metaphors and logical analogues: A question of terminology. Journal of the American Society for Information Science; New York, 51(2), 111-122. doi.org/10.1002/(SICI)10974571(2000)51:2

Heartfield, R., \& Loukas, G. (2018). Detecting semantic social engineering attacks with the weakest link: Implementation and empirical evaluation of a human-as-a-security-sensor framework. Computers \& Security, 76, 101-127. doi: 10.1016/j.cose.2018.02.020

Hsi, S. (2007). Conceptualizing learning from the everyday activities of digital kids. International Journal of Science Education, 29(12), 1509-1529. doi.org/10.1080/09500690701494076

Kaiser, H.F. (1960). The application of electronic computers to factor analysis. Educational and Psychological Measurement. 20(1), 141-151. doi:10.1177/001316446002000116.

Katz, L. G., \& ERIC Clearinghouse on Elementary and Early Childhood Education, U. I. (1993). Dispositions: Definitions and implications for early childhood practices. Perspectives from ERIC/EECE: A Monograph Series, No. 4.

Kirschner, Paul A. \& De Bruyckere, P. (2017). The myths of the digital native and the multitasker. Teaching and Teacher Education, 67, 135-142.

Koc, M., \& Barut, E. (2016). Development and validation of new media literacy scale (NMLS) for university students. Computers in Human Behavior, 63, 834-843. doi.org/10.1016/j.chb.2016.06.035

Kurtz, G., \& Peled, Y. (2016). Digital learning literacies - a validation study. Issues in Informing Science and 


\section{Issues in Information Systems}

Volume 20, Issue 2, pp. 206-215, 2019

Information Technology, 13, 145-158. https://doi.org/10.28945/3479

Owens, J., \& Lilly, F. (2017). The influence of academic discipline, race, and gender on web-use skills among graduate-level students. Journal of Computing in Higher Education, 29(2), 286-308. https://doi.org/10.1007/s12528-017-9137-1

Pawlowski, S.D. \& Jung, Y. (2015). Social representations of cybersecurity by university students and implications for instructional design. Journal of Information Systems Education, 26(4), 281-294.

Pew Research Center, (2018). Social media Social Media Use in 2018. Available at: https://www.pewinternet.org/2018/03/01/social-media-use-in-2018/

Porat, E., Blau, I., \& Barak, A. (2018). Measuring digital literacies: Junior high-school students' perceived competencies versus actual performance. Computers \& Education, 126, 23-36.

Prensky, M. (2001). Digital natives, digital immigrants. On the Horizon. MCB University Press, (9), 5.

Sadaf, A. \& Johnson, B. (2017). Teachers' Beliefs about Integrating Digital Literacy into Classroom Practice: An Investigation Based on the Theory of Planned Behavior. Journal of Digital Learning in Teacher Education, 33(4) 129-137.

Siddiq, F., Hatlevik, O.E., Olsen, R.V., Throndsen, I., \& Scherer, R. (2016). Taking a future perspective by learning from the past - A systematic review of assessment instruments that aim to measure primary and secondary school students' ICT literacy. Educational Research Review, 19, 58-84. doi.org/10.1016/j.edurev.2016.05.002

Sigler, E.A. \& Tallent-Runnels, M.K. (2006). Examining the validity of scores from an instrument designed to measure metacognition of problem solving. Journal of General Psychology, 133(3), 257-76. doi:10.3200/GENP.133.3.256-276.

Tucker, L.R., \& MacCallum, R.C. (1997). Exploratory factor analysis. Unpublished manuscript, Ohio State University, Columbus.

van Deursen, A.J.A.M., Helsper, E.J., \& Eynon, R. (2016). Development and validation of the Internet skills scale (ISS). Information, Communication \& Society, 19(6), 804-823. doi.org/10.1080/1369118X.2015.1078834

van Laar, E., van Deursen, A.J.A.M., van Dijk, J.A.G.M., \& de Haan, J. (2017). The relation between 21st-century skills and digital skills: A systematic literature review. Computers in Human Behavior, 72, 577-588. doi.org/10.1016/j.chb.2017.03.010

Zehner, W. (1981). The family as role model for educating its members: Childhood through adulthood. Paper presented at the National Adult Education Conference, October, 1981. 